\title{
Measuring Efficiency of Generating Electric Processes
}

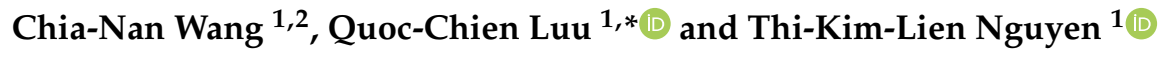 \\ 1 Department of Industrial Engineering and Management, National Kaohsiung University of Science and \\ Technology, Kaohsiung 80778, Taiwan; cn.wang@nkust.edu.tw (C.-N.W.); \\ lien.nguyen0209@gmail.com (T.-K.-L.N.) \\ 2 Department of Industrial Engineering and Management, Fortune Institute of Technology, \\ Kaohsiung 83160, Taiwan \\ * Correspondence: jkie2211@gmail.com; Tel.: +88-609-7965-2251
}

Received: 12 November 2018; Accepted: 19 December 2018; Published: 21 December 2018

check for updates

\begin{abstract}
Electric energy sources are the foundation for supporting for the industrialization and modernization; however, the processes of electricity generation increase $\mathrm{CO}_{2}$ emissions. This study integrates the Holt-Winters model in number cruncher statistical system (NCSS) to estimate the forecasting data and the undesirable model in data envelopment analysis (DEA) to calculate the efficiency of electricity production in 14 countries all over the world from past to future. The Holt-Winters model is utilized to estimate the future; then, the actual and forecasting data are applied into the undesirable model to compute the performance. From the principle of an undesirable model, the study determines the input and output factors as follows nonrenewable and renewable fuels (inputs), electricity generation (desirable output), and $\mathrm{CO}_{2}$ emissions (undesirable output). The empirical results exhibit efficient/inefficient terms over the period from 2011-2021 while converting these fuels into electricity energy and $\mathrm{CO}_{2}$ emissions. The efficiency reveals the environmental effect level from the electricity generation. The analysis scores recommend a direction for improving the inefficient terms via the principle of inputs and undesirable outputs excess and desirable outputs shortfalls in an undesirable model.
\end{abstract}

Keywords: productivity efficiency; Holt-Winters model; undesirable model; data envelopment analysis (DEA)

\section{Introduction}

In recent years, the electricity industry has been extended to meet the demands of growth economic sustainably [1], which provides an energy source for lighting, heating, cooling, transportation, information exchange, i.e., electrical energy is derived from nonrenewable and renewable fuels [2], whereas the renewable fuels include sun, wind, and water, and nonrenewable fuels include oil and natural gas [3]. These fuels are processed to convert to the electricity via rotating turbines; simultaneously, $\mathrm{CO}_{2}$ emissions are produced in electricity production [4]. Thus, the operation process not only generates the electric energy to enhance the economic development [5] but also emits $\mathrm{CO}_{2}$ emissions to increase pollutants and climate change [6]. The aim of this study is to evaluate the conversion valuation from renewable and nonrenewable fuels to electricity and $\mathrm{CO}_{2}$ emissions of 14 countries all over the world from the past to future; thus, we integrate the Holt-Winters and undesirable models to observe the efficiency of the conversion process.

The Holt-Winters model in number cruncher statistical system (NCSS) is used for calculating the forecasting data during the period from 2018-2021 because it can predict the future based on the long time-series, trends, and seasonality [7]. The estimated data are tested by parameters such as alpha, beta, and gamma, and the mean absolute percentage (MAPE) indicator. Next, all actual 
and estimated data are applied into the undesirable model in data envelopment analysis (DEA) to figure out the performance of the conversion process from fuels to electricity generation and $\mathrm{CO}_{2}$ emissions. In DEA, the function of the undesirable model is as same as the directional distance model deal with good (desirable) and bad (undesirable) outputs; however, the directional distance model requires complex input and output factors, i.e., nondirectional input and output variables; further, the undesirable model can solve with desirable and undesirable outputs independently [8]. Moreover, this model presents slacks of each variable in every decision-making unit (DMU), which suggest the improvement direction to the inefficient terms, i.e., increasing the desirable outputs, deducting the inputs and undesirable outputs [9]. By the way, the research discovers the transformation valuation from the primary fuels to the electrical energy and $\mathrm{CO}_{2}$ emissions from past to future. The empirical results assess the efficiency of electricity generation; in addition, they also point out the effect level of electricity production on the environment. Moreover, the analysis results offer a feasible solution to raise the efficiency and reduce the bad effects.

Therefore, to have an electrical energy source that provides for electronic equipment and machines, all primary sources including nonrenewable and renewable, must be put into a production process. This process creates not only electricity production but also $\mathrm{CO}_{2}$ emissions. To reckon out the efficiency of electricity generation from past to future, the Holt-Winters model in NCSS software with the function of forecasting data based on the historical time-series helps to estimate the future data; besides, the undesirable model with the principle of solving both desirable and undesirable outputs equips us to compute the performance of electricity generation in every term.

The research is disposed as follows: Section 1 indicates the basic description of electricity generation, Holt-Winters and undesirable models; Section 2 shows the concept of electricity and the major elements that relate to manufacture the electrical energy, and common application of Holt-Winters and undesirable models; Section 3 explores the source of data and builds up the research methods; Section 4 points out the empirical analysis results and seeks out methods to solve inefficient terms; Section 5 shows the key results, limitations, and future research.

\section{Literature Review}

Electricity is a necessary energy source that assists the daily activities of living, industrial manufacturing, and business. The electrical energy is generated by two kinds of fuels including nonrenewable and renewable fuels, whereas nonrenewable fuels are formed and cannot replenish in a short term; renewable fuels can replenish but the limitation of amount. The primary energy is converted into the electricity by the electric generator and turbine [10]. When the combustion of fuels in the power plants captures $\mathrm{CO}_{2}$ emissions $[11,12]$ that are harmful for environment. As the previous researches, the coal-fired power plant in central Taiwan provided $19 \%$ of electricity consumption in Taiwan, simultaneously emitted large $\mathrm{CO}_{2}$ emissions which caused a serious air pollution in Taichung and neighboring areas [6]. An investigation of $\mathrm{CO}_{2}$ emissions from coal in India power plant showed that one ton of fossil fuels are burned, three quarters of a tone $\mathrm{CO}_{2}$ emissions are emitted [13]. The combustion of fossil fuels generate heat needed to power steam turbines as electricity production, this electricity generation produced approximately $40 \%$ of global $\mathrm{CO}_{2}$ emissions [14]. As a result, these primary fuels are transformed into both electricity and $\mathrm{CO}_{2}$ emissions, the electrical energy source is a useful output which provides energy for light, heating, machine, i.e.; the $\mathrm{CO}_{2}$ emission is an undesirable output of electricity generation process because this emission causes bad effects on environment such as pollutant, and climate change. The usage level of fuels and outputs from electricity production activities in the future is predict by Holt-Winters model in this paper.

NCSS is a statistics software that integrates the exponential smoothing to escalate the prediction data based on the time series, the exponential smoothing consists three procedures, i.e., horizontal, trend, and trend/seasonal [7]. The horizontal only works with the short-term of time series when utilizing a weighted average of the most recent observations without trends or seasonal patterns [15]. The trend expands the forecast series with upward and downward trends; however, this model 
restricts no seasonality [16]. The trend/seasonal procedure can reckon out the upward and downward trends, and seasonal technique with using the Holt-Winters exponential smoothing algorithm [17]. Therefore, the Holt-Winters model was utilized to forecast the future in various researches. For instance, a prediction of Bayesian depended on the additive Holt-Winters model [18]; an investigation of the rainfall pattern in Langat River Basin, Malaysia with the time series within more than 25 years was chosen to discover the future [19]; a forecasting of revenue of Bangabandhu Multipurpose Bridge was computed when focusing on the monthly time series data [20]; a research of future cloud resource provisioning was employed by the algorithm of the Holt-Winters exponential smoothing method to model clod workload with multi-seasonal cycles [21]; and a study of the amount of income at the Department of Transportation Yoyakarta was estimated by the Holt-Winters model and confirmed by the parameters and MAPE indicator [22]. With these characteristics, the Holt-Winters model is a high accuracy forecasting tool with trend and seasonality when observing the long time series. The estimated data are checked by parameters including alpha, beta, and gamma, next the MAPE indicator is also calculated to confirm the accuracy of forecasting valuation. From the previous researches and the rule of Holt-Winters model, the research uses Holt-Winters model for estimating the prediction data based on the selected data of relative factors to electricity generation within seven years.

Slack-based measure (SBM) in DEA can measure the performance with the input excesses and the output shortfalls of decision making unit (DMU) [23], the maximum efficiency is equal 1. Then, the efficiency of SBM is enlarged in order to overcome a limitation for highest score. Its maximum score can be higher than 1 and no DMU has the same score; nevertheless, the super-SBM only approaches desirable outputs [24]. Therefore, Tone (2003) [25] proposed the undesirable model with the presence of bad outputs. This model can solve directly the input and undesirable output excesses and desirable output shortfalls. In the operation process, the bad elements are produced, i.e., carbon dioxit, methan, waste, and so on, thus the undesirable model supports for measuring the productivity efficiency with the presence of bad output factors. For instance, in terms of agriculture, farming not only produces the food but also causes the bad impacts for the environment, Kuo utilized the undesirable model to evaluate the economic and environment factors and recommended the reduction of pollution through the slack analysis of DEA [26]; generating the electricity in nuclear power plants emitted $\mathrm{CO}_{2}$ emissions, the measurement of operational efficiency was applied by the undesirable model [27]; manufacturing cement caused the pollutant environment because of producing $\mathrm{CO}_{2}$ emissions, Ozkan gave an effect level of cement factories in Turkey and suggested a solution to improve the environment based on the efficiency values [28]. As regards the presence of undesirable output, this research uses the undesirable model for assessing the productivity efficiency of generating electricity.

\section{Methods}

\subsection{Data Collection}

Electricity is generated by renewable and nonrenewable fuels that provide an energy source for the light, cooling, heating, and machines. The efficient transformation from these fuels to electricity generation and $\mathrm{CO}_{2}$ emission is analyzed particularly in the study. The selected data of inputs and outputs in 14 countries over the world from 2008 to 2017 are posted on BP [29] (names of the 14 countries are shown in Table 1).

With the principle of dealing among inputs, desirable output, and undesirable output, the undesirable model is a good tool to measure the efficiency of operation processes that produces both good and bad factors. Thus, to measure the efficiency of electricity generation, this study selected nonrenewable and renewable as inputs, generation electricity as desirable output, and $\mathrm{CO}_{2}$ emissions as undesirable output. The basic characteristics of variables are given as follows:

Nonrenewable (input): Coal, natural gas, oil, and nuclear energy are nonrenewable [30] which take part in producing electricity process. The fuels were formed from the buried remains 
of plants and animals that lived millions of years ago; they cannot replenish in a short time. The equation of nonrenewable fuels is given as follows:

$$
\text { Nonrenewable }=\sum(\text { coal }+ \text { gas }+ \text { oil }+ \text { nuclear })
$$

Renewable (input): Renewable energy sources are available and virtually inexhaustible in duration, but the amount of energy is limited. The main kinds of renewable energy are biomass, hydropower, geothermal, wind, and solar [31]. The equation of renewable fuels is given as follows:

$$
\text { Renewable } \left.=\sum \text { (biomass }+ \text { hydropower }+ \text { geothermal }+ \text { wind }+ \text { solar }\right)
$$

Electricity generation (desirable output): The nonrenewable and renewable fuels are metabolized into electricity energy.

- $\mathrm{CO}_{2}$ emissions (undesirable output): The heat or combustion of fuels in electricity generation process produces $\mathrm{CO}_{2}$ emissions. These emissions are undesirable elements that cause bad effects such as environmental pollution and climate change.

Table 1. Name of country.

\begin{tabular}{cccc}
\hline No. & Country & No. & Country \\
\hline 1 & Argentina & 8 & India \\
2 & Brazil & 9 & Mexico \\
3 & Canada & 10 & South Korea \\
4 & China & 11 & Spain \\
5 & Finland & 12 & Sweden \\
6 & France & 13 & United Kingdom \\
7 & Germany & 14 & United State \\
\hline \multicolumn{4}{c}{ Source: BP [29]. }
\end{tabular}

\subsection{Holt-Winters Model}

Holt-Winters model is a prediction tool of exponential smoothing with one for level, one for trend, and one for seasonality in NCSS that was integrated by two methods of Holt (1957) [32] and Winters (1960) [33]. This model allows to calculate short-term forecast with the presence of long-term time series in previous term. Thus, the actual data which relate to electricity generation in 14 countries all over the world with the long time series from 2008 to 2017 are applied into the Holt-Winters model to estimate the short future term from 2018 to 2021. The model can help users to select the best optimal smoothing parameters including $\alpha, \beta, \gamma$ from available valuations to compute an authentic forecasting when depending on the historical time series.

The primary time series is set up as $A_{t}, A_{t+1}, \ldots, A_{t+n}(t=0,1,2, \ldots, n)$, and the prediction time series is observed as $P_{t}, P_{t+1}, \ldots, P_{t+n}(t=0,1,2, \ldots, n)$ " $n$ is the size of the sample"). In the history and forecasting time series, $t$ is also started at a time point with the value from 0 to 1 , and the original algorithm of exponential smoothing is established by the following formula:

$$
\begin{gathered}
P_{t+1}=\alpha A_{t}+(1-\alpha) P_{t} \\
(0 \leq \alpha \leq 1)
\end{gathered}
$$

With the multiplicative seasonality, the seasonal variation is adjusted with the proportional to the level of the time series, the seasonal adjustment is divided by the component. We set up the exponential smoothing with one for level $l_{t}$, one for trend $d_{t}$, and one for seasonality $y_{t}$. The mathematical prediction equation is given as below: 
The exponential smoothing estimate of the level at time $t$ :

$$
\begin{gathered}
l_{t}=\alpha\left(\frac{A_{t}}{P_{t-n}}\right)+(1-\alpha)\left(l_{t-1}+d_{t-1}\right) \\
0<\alpha \leq 1
\end{gathered}
$$

The exponential smoothing estimate of the change with the trend at time $t$ :

$$
\begin{gathered}
d_{t}=\beta\left(l_{t}-l_{t-1}\right)+(1-\beta) d_{t-1} \\
0<\beta \leq 1
\end{gathered}
$$

The exponential smoothing estimate of the seasonal component at time $t$ :

$$
\begin{gathered}
y_{t}=\gamma \frac{P_{t}}{\left(l_{t-1}+d_{t-1}\right)}+(1-\gamma) y_{t-n} \\
0<\gamma \leq 1
\end{gathered}
$$

Let step ahead prediction at time $t$ is $h$. Hence, the forecasting algorithm at the time $t$ is given as follows:

$$
P_{t+h}=\left(l_{t}+h d_{t}\right) y_{t+h-n}
$$

To have high accuracy, the forecasting values must be checked by the mean absolute percentage error (MAPE) index.

$$
\text { MAPE }=\frac{1}{n} \sum_{t=1}^{n}\left|\frac{A_{t}-P_{t}}{A_{t}}\right| \times 100
$$

The categorization of MAPE indicator shows that the forecasting value is highly accuracy when the MAPE is lower than $10 \%$; the indicator between $10 \%$ and $20 \%$ is a good prediction valuation; the reasonable forecasting value is from $20 \%$ to $50 \%$; the prediction data are inaccurate when being more than $50 \%$ [34]. Therefore, the model or data will be reselected if the forecasting valuations receive MAPE above $50 \%$, or optimal smoothing parameters without range from 0 to 1 .

\subsection{Undesirable Model}

In data envelopment analysis, the undesirable model is an extended model that provides a solution of non-parametric DEA scheme for measuring the efficiency among inputs, good outputs and bad outputs variables, this model deals with the undesirable outputs of production. In this study, we use the undesirable model for solving the electricity generation in 14 countries all over the world. The countries are called $\mathrm{DMU}_{\mathrm{s}}$; nonrenewable and renewable are called inputs; electricity generation and $\mathrm{CO}_{2}$ emissions are called good, and bad outputs, respectively. We set up DMUs with three factors including inputs $U=\left(u_{i j}\right) \in R^{+}$, good output $V^{g}=\left(v_{i j}^{g}\right) \in R^{+}$, bad output $V^{b}=\left(v_{i j}^{b}\right) \in R^{+}$. Selected data set are positive so that $U, V^{g}$, and $V^{b}$ are higher than 0 . The production possibility of A DMU is given as follows:

$$
P=\left(u, v^{g}, v^{b}\right)
$$

whereas

$$
u \geq U \lambda, v^{g} \leq V^{g} \lambda, v^{b} \geq V^{b} \lambda, \lambda \geq 0
$$

A $\operatorname{DMU}\left(u_{0}, v_{0}^{g}, v_{0}^{b}\right)$ has efficiency when there is no vector $\left(u, v^{g}, v^{b}\right) \in P$, and $u_{0} \geq u, v_{0}^{g} \geq$ $v^{g}, v_{0}^{b} \geq v^{b}$

The slacks, i.e., $s^{-}, s^{b}, s^{+}$are inputs and undesirable output excesses, and desirable output shortfall, respectively; and $\lambda$ is the weight vector. The number of inputs, desirable output, and undesirable output factors are $h, s_{1}, s_{2}$ respectively. Based on the equation of SBM model [23], the undesirable outputs model is modified as below: 


$$
\rho^{*}=\min \frac{1-\frac{1}{h} \sum_{i=1}^{h} \frac{s_{i}^{-}}{u_{i 0}}}{1+\frac{1}{s_{1}+s_{2}}\left(\sum_{r=1}^{s_{1}} \frac{s_{r}^{g}}{v_{r 0}^{g}}+\sum_{r=1}^{s_{2}} \frac{s_{r}^{b}}{v_{r 0}^{b}}\right)}
$$

whereas

$$
u_{0}=U \lambda+s^{-} ; v_{0}^{g}=V^{g} \lambda-s^{g} ; v_{0}^{b}=V^{b} \lambda+s^{b} ; s^{-} \geq 0, s^{g} \geq 0, s^{b} \geq 0, \lambda \geq 0
$$

All slacks and $\lambda$ are positive.

When $w_{i}, w_{r}^{g}, w_{r}^{b}$ are weights to input $i$, desirable output $w_{r}^{g}$, and undesirable output $w_{r}^{b}$, respectively, the equation of undesirable outputs model [24,25] is given as below:

$$
\rho^{*}=\min \frac{1-\frac{1}{h} \sum_{i=1}^{h} \frac{w_{i}^{-} s_{i}^{-}}{u_{i 0}}}{1+\frac{1}{s_{1}+s_{2}}\left(\sum_{r=1}^{s_{1}} \frac{w_{r}^{g} s_{r}^{g}}{v_{r 0}^{g}}+\sum_{r=1}^{s_{2}} \frac{w_{r}^{b} s_{r}^{b}}{v_{r 0}^{b}}\right)}
$$

whereas

$$
\sum_{r=1}^{s_{1}} w_{r}^{g}=s_{1} ; \sum_{r=1}^{s_{2}} w_{r}^{b}=s_{2} ;\left(w_{r}^{g} \geq 0, w_{r}^{b} \geq 0\right)
$$

The value of $\rho^{*}$ is between 0 and 1 . Set up an optimal solution, the parameters are $\lambda^{*}, s^{-*}, s^{g+*}$, and $s^{b+*}$. When $\rho^{*}=1$, simultaneously $s^{-*}=0, s^{g+*}=0$, and $s^{b+*}=0, \mathrm{~A}$ $\operatorname{DMU}\left(u_{0}, v_{0}^{g}, v_{0}^{b}\right)$ obtains the efficiency. If $\rho^{*}<1, \mathrm{~A} D M U\left(u_{0}, v_{0}^{g}, v_{0}^{b}\right)$ is inefficient. Hence, the productivity efficiency value is worse and needs to improve, the efficiency of $\operatorname{ADMU}\left(u_{0}, v_{0}^{g}, v_{0}^{b}\right)$ must be improved to reach the efficiency by deleting the excesses in inputs and bad outputs, and rising the shortfalls in good outputs as follows:

$$
\begin{aligned}
& u_{0}-s^{-*} \Rightarrow u_{0} \\
& v_{0}^{g}+s^{g *} \Rightarrow v_{0}^{g} \\
& v_{0}^{b}-s^{b *} \Rightarrow v_{0}^{b}
\end{aligned}
$$

According to Equation (12), in this research, the inefficient terms will be treated by increasing electricity generation, and deducting renewable fuels, nonrenewable fuels, and $\mathrm{CO}_{2}$ emissions. Moreover, the environmental efficiency value will be better when $\mathrm{CO}_{2}$ emissions are cut down.

Next, set the dual variable vectors $x, y^{d}, y^{u}$. The dual program in the variable $x, y^{d}, y^{u}$ for constant return to scale [24] is determined basing on the dual side of the linear program.

$$
\max y^{g} v_{0}^{g}-x u_{0}-y^{b} v_{0}^{b}
$$

where

$$
\begin{aligned}
& y^{g} V^{g}-x U-y^{b} V^{b} \leq 0 \\
& x \geq \frac{1}{h}\left[\frac{1}{u_{0}}\right]
\end{aligned}
$$

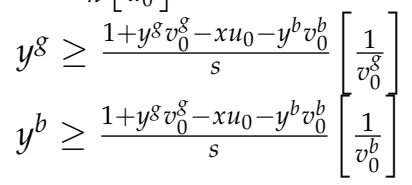

The virtual prices of inputs and bad outputs are $x$ and $y^{b}$, respectively, and the price of good outputs is $y^{g}$. The optimal virtual costs and prices for $\mathrm{DMU}_{0}$ approach the dual program when the profit $y^{g} v_{0}^{g}-x u_{0}-y^{b} v_{0}^{b}$ does not exceed zero. The weights of desirable and undesirable variables [24] are presented as below: 


$$
\rho^{*}=\min \frac{1-\frac{1}{h} \sum_{i=1}^{h} \frac{w_{i}^{-} s_{i o}^{-}}{u_{i o}}}{1+\frac{1}{s_{1}+s_{2}}\left(\sum_{r=1}^{s_{1}} \frac{w_{r}^{g} S_{r}^{g}}{v_{r o}^{g}}+\sum_{r=1}^{s_{2}} \frac{w_{r}^{b} b_{r}^{b}}{v_{r o}^{b}}\right)}
$$

whereas

$$
\begin{aligned}
& h=\sum_{i=1}^{h} w_{i}^{-},\left(w_{i}^{-} \geq 0\right) \\
& s_{1}+s_{2}=\sum_{r=1}^{s_{1}} w_{r}^{g}+\sum_{r=1}^{s_{2}} w_{r}^{b},\left(w_{r}^{g} \geq 0 ; w_{r}^{b} \geq 0\right)
\end{aligned}
$$

Variables including $w_{i}, w_{r}^{g}$, and $w_{r}^{b}$ are the weights to input $i$; and $r$ is desirable and undesirable output, these weights are positive data.

$\mathrm{DMU}_{0}$ has efficiency if $\rho^{*}=1$. On the other hand, $\mathrm{DMU}_{0}$ does not have inefficiency if $\rho^{*}<1$. Thus, the efficiency will be improved if the input excesses are reduced; the output shortfalls are increased.

\section{Results}

\subsection{Data Analysis}

From the list of 14 countries and selected variables in Section 3.2, we calculate the actual valuation of each factor in every country based on primary data [30]. Argentina is chosen as an example.

From (1), the value of nonrenewable fuels:

$$
\text { Nonrenewable }=\sum 1.5+37.1+25.5+1.7
$$

From (2), the value of renewable fuels:

$$
\text { Renewable }=\sum 0.635+8.4+(\text { geothermal }+ \text { wind }+ \text { solar }) 0.4
$$

The output variables, including electricity generation and $\mathrm{CO}_{2}$ emissions are available to post on BP [29]. The summarized data of 14 countries over the period 2008-2017 are presented in Tables A1 and A2. The valuations of input and output factors are ranged from 1.146 to 9232.6 , so that they are positive and meaning. Hence, these values are highly appraised utilizing the Holt-Winters model to predict the future and the undesirable model for determining the efficiency.

\subsection{Forecasting Valuations}

Based on the historical data, the research carries out an investigation of future terms. An accuracy prediction valuation of the Holt-Winters model in exponential smoothing must be satisfied with the space of smoothing constants from 0 to 1 . In this study, the parameters, including alpha, beta, and gamma, are set up as standard points, i.e., 0.3, 0.4, and 0.001, respectively. Moreover, the forecasting data will be rechecked by MAPE index to ensure a high accuracy level.

Table 2 expresses the classification of MAPE indications of prediction values. The percentages of nonrenewable, renewable, electricity, and $\mathrm{CO}_{2}$ emissions in 14 countries are from $1.22 \%$ to $17.67 \%$, and their average is $3.74 \%$. By the way, the MAPEs of the forecasting data receive an appreciate qualification. Therefore, the Holt-Winters model is a good forecasting tool of electricity aspects in 14 countries over the world during the term from 2018-2021; these valuations are highly accurate and will be used for employing the performance measurement in the future time for the next step. The forecasting results are presented in Tables A3-A6. 
Table 2. MAPE indications of forecasting valuations.

\begin{tabular}{ccccc}
\hline Country & NRL (Mtons) & REL (Mtons) & EGN (TWh) & CO $_{\mathbf{2}}$ (Mtons) \\
\hline Argentina & $2.61 \%$ & $4.40 \%$ & $1.57 \%$ & $2.82 \%$ \\
Brazil & $6.58 \%$ & $3.31 \%$ & $3.69 \%$ & $7.60 \%$ \\
Canada & $2.17 \%$ & $2.36 \%$ & $2.06 \%$ & $2.48 \%$ \\
China & $3.95 \%$ & $5.33 \%$ & $4.57 \%$ & $4.36 \%$ \\
Finland & $3.90 \%$ & $7.00 \%$ & $3.23 \%$ & $6.55 \%$ \\
France & $1.39 \%$ & $6.04 \%$ & $2.13 \%$ & $3.17 \%$ \\
Germany & $2.45 \%$ & $3.73 \%$ & $1.98 \%$ & $1.96 \%$ \\
India & $1.23 \%$ & $4.82 \%$ & $1.52 \%$ & $1.26 \%$ \\
Mexico & $2.21 \%$ & $9.95 \%$ & $1.34 \%$ & $2.30 \%$ \\
South Korea & $2.45 \%$ & $4.31 \%$ & $3.26 \%$ & $3.36 \%$ \\
Spain & $5.01 \%$ & $13.88 \%$ & $1.49 \%$ & $5.68 \%$ \\
Sweden & $3.43 \%$ & $5.68 \%$ & $4.08 \%$ & $3.35 \%$ \\
United Kingdom & $1.88 \%$ & $9.31 \%$ & $1.53 \%$ & $3.90 \%$ \\
United State & $1.51 \%$ & $4.01 \%$ & $1.22 \%$ & $1.95 \%$ \\
\hline Average & \multicolumn{5}{c}{$3.74 \%$} \\
\hline
\end{tabular}

Note: NRL: Nonrenewable; REL: Renewable; EGN: Electricity generation; $\mathrm{CO}_{2}: \mathrm{CO}_{2}$ emissions.

\subsection{Productivity Efficiency}

Nonrenewable and renewable fuels are utilized to generate the electrical energy that supports the daily life and activities in manufacturing process. However, the electricity generation process emits $\mathrm{CO}_{2}$ emissions which are derived from combusting fuels. The productivity efficiency from fuels to electricity and $\mathrm{CO}_{2}$ emissions in 14 countries is determined by undesirable model.

From the actual and estimated data of 14 countries during the period 2008-2021, the research applied the undesirable model in DEA into counting the efficiency of generating electricity process. According to the principle of DEA, input and output factors must have an isotonic relationship. The undesirable model is proposed by a non-parametric DEA scheme for measuring the efficiency [24] so the rank correlation coefficient of Spearman with a nonparametric measure of rank correlation is utilized to assess the relationship between variables, their correlations are from -1 to +1 . When the correlation is equal 1, it will have a perfect monotonic relationship. Francis et al indicated that there are three types of correlation in DEA including between inputs and outputs; among inputs only; among outputs only [35], but this study explores five types of correlation including between inputs and desirable output; between inputs and undesirable output; among inputs only; among desirable outputs only; and among undesirable outputs only, their values are ranged from 0.75768 to 1 as shown in Tables A7 and A8. These results denote that the inputs, desirable and undesirable outputs have a strong positive and meaningful relationship. In particular, the relationships among inputs only; among desirable outputs only; and among undesirable outputs only have a perfect monotonic correlation when their values are equal 1; remaining relationships have a good monotonic correlation when their values are ranged from 0.75768 to 0.99699 . Thus, these variables have an appreciate qualification.

Observing Tables 3 and 4, most efficiencies of 14 countries during the period 2008-2021 fluctuate consecutively excluding France, Korea, and Sweden. Three countries including France, Korea, and Sweden always obtain the performance and keep a stable valuation while converting fuels into electricity and $\mathrm{CO}_{2}$ emissions. The productivity efficiency is proved by their slacks, the excesses and shortfall are equal 0. Besides, Finland received the efficiency in two years 2009-2010 when its score was 1 ; and its slacks were 0 . As a result, these terms have a high effectiveness in electric generation process; in addition, the $\mathrm{CO}_{2}$ emissions are emitted while producing renewable and nonrenewable fuels, they reach a standard and balance level.

On the other hand, others countries and remaining terms of Finland reach the shortfalls as 0 , but their scores are under 1 ; and most excesses are more than 0 . The empirical results show that the efficiencies have a downward and upward trend smoothly within 0.405 and 0.785 , simultaneously 
reveal inefficient terms. India and Mexico have a same performance movement, they also augment the efficiency in four consecutive years with the previous term 2013-2016 and four years in future time. Although, they make efforts, the maximum efficiency of India and Mexico is 0.785 and 0.595 , respectively. Remaining terms of Finland display a large fluctuation, it has a period that is decreased in five continual years 2014-2018; the forecasted score shows that it can be dropped deeply to 0.665 in 2020. Brazil and United Kingdom exhibit a similar dramatic efficiency increase and then reduce smoothly in whole term except 2013 and 2015. Argentina and United State rise and deduct with a same variation over the period of 2010-2012 and 2014-2021; besides, Argentina extended its score in 2009 and 2013, United State reserved back. Germany has an unceasing change, i.e., one year rises and one year decreases softly except the period 2011-2015 was felt consecutively. China always expands with previous time and future time, but its score is still at the median values from 0.405 to 0.671 . The scores of Canada are between 0.532 and 0.627 , its efficiency was downed within four continual years from 2010 to 2013. Spain only advances in 2013 and 2020, in contrary slumps in others terms.

Table 3. Productivity efficiency over the period 2008-2014.

\begin{tabular}{cccccccc}
\hline Country & $\mathbf{2 0 0 8}$ & $\mathbf{2 0 0 9}$ & $\mathbf{2 0 1 0}$ & $\mathbf{2 0 1 1}$ & $\mathbf{2 0 1 2}$ & $\mathbf{2 0 1 3}$ & $\mathbf{2 0 1 4}$ \\
\hline Argentina & 0.484 & 0.499 & 0.464 & 0.428 & 0.479 & 0.485 & 0.455 \\
Brazil & 0.503 & 0.524 & 0.508 & 0.488 & 0.476 & 0.476 & 0.487 \\
Canada & 0.603 & 0.627 & 0.593 & 0.582 & 0.571 & 0.566 & 0.569 \\
China & 0.405 & 0.409 & 0.439 & 0.463 & 0.469 & 0.533 & 0.552 \\
Finland & 0.852 & 1.000 & 1.000 & 0.833 & 0.798 & 0.831 & 0.806 \\
France & 1.000 & 1.000 & 1.000 & 1.000 & 1.000 & 1.000 & 1.000 \\
Germany & 0.646 & 0.627 & 0.629 & 0.574 & 0.607 & 0.602 & 0.595 \\
India & 0.481 & 0.458 & 0.466 & 0.505 & 0.492 & 0.505 & 0.561 \\
Mexico & 0.442 & 0.441 & 0.436 & 0.447 & 0.446 & 0.452 & 0.469 \\
Korea & 1.000 & 1.000 & 1.000 & 1.000 & 1.000 & 1.000 & 1.000 \\
Spain & 0.685 & 0.678 & 0.625 & 0.568 & 0.63 & 0.632 & 0.591 \\
Sweden & 1.000 & 1.000 & 1.000 & 1.000 & 1.000 & 1.000 & 1.000 \\
United Kingdom & 0.553 & 0.565 & 0.562 & 0.559 & 0.521 & 0.510 & 0.521 \\
United State & 0.720 & 0.711 & 0.691 & 0.637 & 0.684 & 0.647 & 0.637 \\
\hline
\end{tabular}

Table 4. Productivity efficiency over the period 2015-2021.

\begin{tabular}{cccccccc}
\hline Country & $\mathbf{2 0 1 5}$ & $\mathbf{2 0 1 6}$ & $\mathbf{2 0 1 7}$ & $\mathbf{2 0 1 8}$ & $\mathbf{2 0 1 9}$ & $\mathbf{2 0 2 0}$ & $\mathbf{2 0 2 1}$ \\
\hline Argentina & 0.472 & 0.498 & 0.479 & 0.487 & 0.483 & 0.499 & 0.494 \\
Brazil & 0.471 & 0.481 & 0.479 & 0.471 & 0.469 & 0.468 & 0.467 \\
Canada & 0.576 & 0.555 & 0.555 & 0.541 & 0.546 & 0.532 & 0.536 \\
China & 0.568 & 0.618 & 0.630 & 0.642 & 0.650 & 0.658 & 0.671 \\
Finland & 0.774 & 0.770 & 0.757 & 0.718 & 0.719 & 0.665 & 0.669 \\
France & 1.000 & 1.000 & 1.000 & 1.000 & 1.000 & 1.000 & 1.000 \\
Germany & 0.576 & 0.597 & 0.562 & 0.565 & 0.542 & 0.550 & 0.528 \\
India & 0.596 & 0.657 & 0.656 & 0.696 & 0.711 & 0.774 & 0.785 \\
Mexico & 0.514 & 0.498 & 0.510 & 0.519 & 0.552 & 0.555 & 0.595 \\
Korea & 1.000 & 1.000 & 1.000 & 1.000 & 1.000 & 1.000 & 1.000 \\
Spain & 0.587 & 0.585 & 0.581 & 0.570 & 0.559 & 0.560 & 0.549 \\
Sweden & 1.000 & 1.000 & 1.000 & 1.000 & 1.000 & 1.000 & 1.000 \\
United Kingdom & 0.536 & 0.564 & 0.550 & 0.508 & 0.461 & 0.453 & 0.418 \\
United State & 0.656 & 0.666 & 0.631 & 0.650 & 0.638 & 0.654 & 0.643 \\
\hline
\end{tabular}

The above analysis denotes that the average valuation of Argentina is lowest; China is a unique country that always raises its scores with the large exertion. The scores in Tables 3 and 4 describe the efficient/inefficient terms of every country during the period from 2008 to 2021 particularly; whereas many inefficient terms are pointed out. Based on the rule of undesirable model, the inefficient terms are suggested to improve their scores by reducing the excesses such as nonrenewable, renewable, and $\mathrm{CO}_{2}$ emissions; or deducting these excesses, simultaneously increasing the shortfall (electricity generation). 


\subsection{Discussion}

The position of the pathway of the production in 14 countries from past to future is shown in Figure 1.

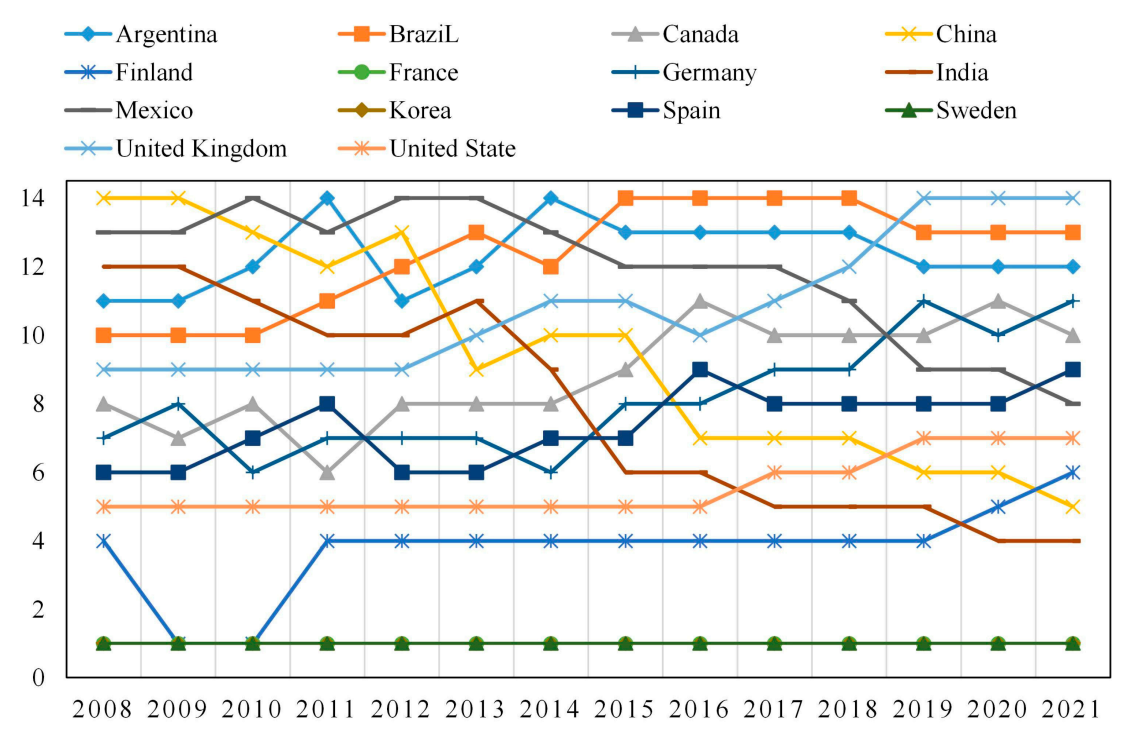

Figure 1. Ranking the pathway of production.

France, Korea, and Sweden over the period from 2008-2021, and Finland from 2009 to 2010 are explored to obtain a good productivity efficiency of conversation progress from nonrenewable and renewable fuels to electricity and $\mathrm{CO}_{2}$ emissions through electric generators and turbines. France, Korea, and Sweden are excellent countries, as their scores always maintain a stable and qualified valuation. The empirical results denote that Finland from 2009 to 2010 and these countries are ranked in the first position of electricity generation.

In contrary, the remaining countries and terms of Finland do not attain the productivity efficiency because their estimated scores are less than 1 and always fluctuate in every year. According to the final analysis result, 12 remaining countries, excluding Finland, always have the worst performance. These countries do not approach the top ranking, which only ranges from 5 to 14 from past to future. Especially, the forecasting scores indicate that the efficiency of Argentina, Brazil, Canada, Germany, and the United Kingdom will be dropped consecutively in the future; in addition, their position will remain at the bottom points. China and India demonstrate an upward trend over the whole term, and they can increase sharply in the future; however, their efforts have not reached the productivity efficiency. Mexico, Spain, and United State display fluctuations smoothly in every year.

The empirical results discover some inefficient terms that they must be improved. Section 4.3 suggests a solution based on the principle of an undesirable model. According to the previous researches, the $\mathrm{CO}_{2}$ emissions from the renewable fuels are less than non-renewable fuels [36]. Thus, the $\mathrm{CO}_{2}$ emissions can be cut down by augmenting the renewable fuels and by reducing the non-renewable fuels. By the way, the air pollutants from emissions will be reduced, and the environment will be restored.

\section{Conclusions}

Economic development requires a large demand of electricity energy sources to operate machines in households and factories, so the extension of electricity generation is necessary to meet with the need of users. Augmenting the electrical energy is accompanied by increasing $\mathrm{CO}_{2}$ emissions. The efficient conversation from primary fuels to electricity generation and $\mathrm{CO}_{2}$ emissions over the period from 2008 to 2021 is employed by combining the Holt-Winters and undesirable models. 
Estimated data in the period of 2018-2021 are calculated by the Holt-Winters model based on the historical data over the period from 2008-2017. The forecasting result describes the usage of nonrenewable and renewable fuels, electricity generation, and $\mathrm{CO}_{2}$ emissions in the future. The prediction data reveal high accuracy valuations when the average of MAPE indicator is $3.74 \%$.

From the actual and estimated data of variables, including nonrenewable fuel, renewable fuel, electricity generation, and $\mathrm{CO}_{2}$ emissions in 14 countries all over the world during the period from 2008-2021, the study observes the scores that are calculated by the undesirable model to evaluate the productivity efficiency of the electricity production process in electricity industry. The empirical results manifest the impact level of electricity industry on the environment. In addition, the slacks propose a solution to improve the inefficient terms.

The study determines the productivity efficiency while converting the primary fuels to electricity generation and $\mathrm{CO}_{2}$ emissions, but limitations remain. First, inputs and outputs are not posted, so the next study needs to have more variables, e.g., employees, equipment, and profit, to assess depth and specification of electricity generation. Second, the undesirable model only gives the maximum efficiency as 1; and, as any countries (DMU) approach the performance, they are at the same top position. Thus, ranking countries will be more specific if the further research applies a super-SBM model into computing the scores. Moreover, estimating the efficiency change of each country will more specific, and future research should use models such as Windows, Malmquist Productivity Index, or bootstrap DEA [37].

Author Contributions: C.-N.W. guided the analysis method, and the research direction, found the solutions, and edited the content; Q.-C.L. designed research framework, collected the data, analyzed the empirical result and wrote the manuscript; T.-K.-L.N. analyzed the data. All authors contributed in issuing the final result.

Funding: This research was partly supported by National Kaohsiung University of Science and Technology, and MOST107-2622-E-992-012-CC3 from the Ministry of Sciences and Technology in Taiwan.

Acknowledgments: The authors appreciate the support from National Kaohsiung University of Science and Technology and Ministry of Sciences and Technology in Taiwan.

Conflicts of Interest: The authors declare no conflict of interest.

\section{Appendix A}

Table A1. Description of historical data over the period of 2008-2012.

\begin{tabular}{cccccc}
\hline Indicator & Year & REL (Mtons) & NRL (Mtons) & CO $_{\mathbf{2}}$ (Mtons) & EGN (TWh) \\
\hline Max & & 151.690 & 2181.400 & 7351.800 & 4390.100 \\
Min & \multirow{2}{*}{2008} & 1.150 & 25.200 & 57.400 & 77.900 \\
Average & 42.280 & 466.610 & 1342.850 & 913.870 \\
SD & & 46.990 & 688.120 & 2166.050 & 1265.210 \\
\hline Max & & 151.520 & 2179.300 & 7680.700 & 4206.500 \\
Min & \multirow{2}{*}{2009} & 4360 & 24.300 & 53.900 & 72.500 \\
Average & & 48.650 & 461.630 & 1329.730 & 909.810 \\
SD & & 687.280 & 2184.110 & 1266.610 \\
\hline Max & & 178.480 & 2314.400 & 8104.900 & 4394.300 \\
Min & 2010 & 47.810 & 26.400 & 57.000 & 81.100 \\
Average & & 53.670 & 483.960 & 1393.680 & 976.610 \\
SD & & 721.690 & 2295.140 & 1375.740 \\
\hline Max & & 180.470 & 2511.700 & 8792.300 & 4713.000 \\
Min & \multirow{2}{*}{2011} & 50.240 & 23.900 & 53.500 & 73.700 \\
Average & & 57.070 & 756.970 & 1439.470 & 1020.180 \\
SD & & 226.700 & 2574.400 & 8966.300 & 4987.600 \\
Max & & 2.080 & 500.420 & 1447.790 & 1045.390 \\
Min & \multirow{2}{*}{2012} & 54.030 & 756.710 & 2440.610 & 1498.040 \\
Average & & 64.310 & &
\end{tabular}


Table A2. Description of historical data over the period of 2013-2017.

\begin{tabular}{cccccc}
\hline Indicator & Year & REL (Mtons) & NRL (Mtons) & CO $_{2}$ (Mtons) & EGN (TWh) \\
\hline Max & & 250.450 & 2659.000 & 9204.200 & 5431.600 \\
Min & \multirow{2}{*}{2013} & 2.520 & 22.300 & 49.000 & 71.400 \\
Average & & 57.590 & 512.840 & 1483.610 & 1085.410 \\
SD & & 69.370 & 780.740 & 2508.360 & 1585.880 \\
\hline Max & & 291.510 & 2684.600 & 9206.500 & 5649.600 \\
Min & \multirow{2}{*}{2014} & 3.040 & 21.100 & 45.800 & 68.200 \\
Average & & 61.840 & 516.860 & 1490.500 & 1109.860 \\
SD & & 77.890 & 789.920 & 2519.750 & 1634.970 \\
\hline Max & & 318.950 & 2693.500 & 9163.200 & 5814.600 \\
Min & \multirow{2}{*}{2015} & 3.590 & 20.600 & 44.300 & 68.800 \\
Average & & 64.760 & 517.460 & 1480.660 & 1128.480 \\
SD & & 73.800 & 788.820 & 2495.860 & 1664.680 \\
\hline Max & & 344.510 & 2704.700 & 9113.600 & 6133.200 \\
Min & \multirow{2}{*}{2016} & 4.090 & 21.400 & 46.900 & 68.800 \\
Average & & 68.740 & 520.460 & 1479.260 & 1158.490 \\
SD & & 91.100 & 789.040 & 2477.970 & 1730.360 \\
\hline Max & & 370.350 & 2763.900 & 9232.600 & 6495.100 \\
Min & \multirow{2}{*}{2017} & 4.710 & 20.500 & 45.000 & 67.900 \\
Average & & 73.270 & 526.060 & 1493.240 & 1188.810 \\
SD & & 98.260 & 799.380 & 2501.370 & 1796.990 \\
\hline
\end{tabular}

Table A3. Prediction values of 14 countries in 2018.

\begin{tabular}{ccccc}
\hline Country & NRL (Mtons) & REL (Mtons) & EGN (TWh) & CO $_{\mathbf{2}}$ (Mtons) \\
\hline Argentina & 81.26 & 13.21 & 153.8 & 198.26 \\
Brazil & 213.19 & 125.39 & 633.56 & 530.81 \\
Canada & 249.84 & 101.55 & 685.86 & 553.95 \\
China & 2923.33 & 445.59 & 7154.89 & 9743.92 \\
Finland & 19.89 & 7.78 & 66.96 & 42.19 \\
France & 213.37 & 26.54 & 565.97 & 300.54 \\
Germany & 280.23 & 57.41 & 662.76 & 761.88 \\
India & 743.59 & 55.15 & 1617.32 & 2494.94 \\
Mexico & 184.01 & 12.72 & 330.23 & 489.67 \\
South Korea & 302.31 & 5.59 & 599.16 & 700.69 \\
Spain & 108.87 & 26.85 & 271 & 275.28 \\
Sweden & 32.91 & 22.38 & 167.7 & 46.05 \\
United Kingdom & 165.18 & 27.44 & 326.33 & 396.08 \\
United State & 2090.91 & 198.62 & 4367.92 & 5109.01 \\
\hline
\end{tabular}

Table A4. Prediction values of 14 countries in 2019.

\begin{tabular}{ccccc}
\hline Country & NRL (Mtons) & REL (Mtons) & EGN (TWh) & CO $_{\mathbf{2}}$ (Mtons) \\
\hline Argentina & 81.11 & 13.83 & 156.72 & 197.39 \\
Brazil & 213.31 & 126.45 & 636.56 & 530.44 \\
Canada & 250.09 & 104.66 & 701.89 & 552.9 \\
China & 3000.26 & 469.16 & 7574.8 & 9936.29 \\
Finland & 19.13 & 7.58 & 64.74 & 39.9 \\
France & 210.48 & 25.49 & 558.64 & 296.26 \\
Germany & 275.53 & 63.05 & 657.07 & 752.73 \\
India & 777.14 & 59.5 & 1716.54 & 2615.76 \\
Mexico & 183.97 & 11.54 & 333.37 & 487.96 \\
South Korea & 305.1 & 6.36 & 606.48 & 708.29 \\
Spain & 107.27 & 26.31 & 265 & 274.9 \\
Sweden & 31.61 & 22.57 & 165.43 & 44.3 \\
United Kingdom & 159.11 & 35.18 & 319.99 & 373.97 \\
United State & 2067.36 & 216.23 & 4306.83 & 5006.32 \\
\hline
\end{tabular}


Table A5. Prediction values of 14 countries in 2020.

\begin{tabular}{ccccc}
\hline Country & NRL (Mtons) & REL (Mtons) & EGN (TWh) & CO $_{\mathbf{2}}$ (Mtons) \\
\hline Argentina & 84.12 & 13.77 & 160.67 & 204.89 \\
Brazil & 221.04 & 128.21 & 657.96 & 550.18 \\
Canada & 256.1 & 105.33 & 704.45 & 565.09 \\
China & 3041.58 & 559.47 & 8031.01 & 9986.88 \\
Finland & 18.95 & 8.42 & 65.04 & 39.05 \\
France & 208.26 & 28.4 & 563.34 & 291.42 \\
Germany & 277 & 68.5 & 674.34 & 758.73 \\
India & 817.27 & 61.96 & 1846.08 & 2757.14 \\
Mexico & 187.49 & 13.64 & 342.59 & 496.78 \\
South Korea & 312.33 & 7.62 & 623.2 & 719.94 \\
Spain & 106.97 & 27.48 & 264.55 & 272.97 \\
Sweden & 32.91 & 23.01 & 171.55 & 44.46 \\
United Kingdom & 156.47 & 38.77 & 315.46 & 364.17 \\
United State & 2086.24 & 222.26 & 4361.02 & 5027.5 \\
\hline
\end{tabular}

Table A6. Prediction values of 14 countries in 2021.

\begin{tabular}{ccccc}
\hline Country & NRL (Mtons) & REL (Mtons) & EGN (TWh) & CO $_{\mathbf{2}}$ (Mtons) \\
\hline Argentina & 83.96 & 14.43 & 163.72 & 203.97 \\
Brazil & 221.15 & 129.29 & 661.02 & 549.74 \\
Canada & 256.34 & 108.58 & 720.94 & 564 \\
China & 3121.72 & 587.73 & 8502.27 & 10184.25 \\
Finland & 18.22 & 8.19 & 62.89 & 36.94 \\
France & 205.45 & 27.23 & 556.05 & 287.27 \\
Germany & 272.36 & 75.24 & 668.51 & 749.62 \\
India & 854.1 & 66.87 & 1959.11 & 2890.56 \\
Mexico & 187.45 & 12.33 & 345.83 & 495.04 \\
South Korea & 315.21 & 8.63 & 630.78 & 727.73 \\
Spain & 105.39 & 26.93 & 258.7 & 272.59 \\
Sweden & 31.61 & 23.21 & 169.22 & 42.77 \\
United Kingdom & 150.74 & 50.08 & 309.33 & 343.91 \\
United State & 2062.74 & 242.11 & 4300.05 & 4926.57 \\
\hline
\end{tabular}

Table A7. Correlation over the period of 2008-2011.

\begin{tabular}{cccccc}
\hline Variable & Year & REL (Mtons) & NRL (Mtons) & CO $_{2}$ (Mtons) & EGN (TWh) \\
\hline REL (Mtons) & & 1 & 0.75768 & 0.77861 & 0.75977 \\
NRL (Mtons) & 2008 & 0.75768 & 1 & 0.98410 & 0.99290 \\
$\mathrm{CO}_{2}$ (Mtons) & & 0.77861 & 0.98410 & 1 & 0.9579 \\
$\mathrm{EGN}$ (TWh) & & 0.75977 & 0.99290 & 0.95790 & 1 \\
\hline $\mathrm{REL}$ (Mtons) & & 1 & 0.77524 & 0.77863 & 0.78978 \\
$\mathrm{NRL}$ (Mtons) & \multirow{2}{*}{2009} & 0.77524 & 1 & 0.98345 & 0.99295 \\
$\mathrm{CO}$ (Mtons) & & 0.77863 & 0.98345 & 1 & 0.95714 \\
$\mathrm{EGN}$ (TWh) & & 0.78978 & 0.99295 & 0.95714 & 1 \\
\hline $\mathrm{REL}$ (Mtons) & & 1 & 0.80595 & 0.81691 & 0.81697 \\
$\mathrm{NRL}$ (Mtons) & \multirow{2}{*}{2010} & 0.80595 & 1 & 0.98469 & 0.99615 \\
$\mathrm{CO}$ (Mtons) & & 0.81691 & 0.98469 & 1 & 0.96781 \\
$\mathrm{EGN}$ (TWh) & & 0.81697 & 0.99615 & 0.96781 & 1 \\
\hline $\mathrm{REL}$ (Mtons) & & 1 & 0.82944 & 0.81951 & 0.84875 \\
$\mathrm{NRL}$ (Mtons) & \multirow{2}{*}{2011} & 0.82944 & 1 & 0.98535 & 0.99717 \\
$\mathrm{CO}$ (Mtons) & & 0.81951 & 0.98535 & 1 & 0.97215 \\
$\mathrm{EGN}$ (TWh) & & 0.84875 & 0.99717 & 0.97215 & 1 \\
\hline
\end{tabular}


Table A8. Correlation over the period of 2012-2021.

\begin{tabular}{|c|c|c|c|c|c|}
\hline Variable & Year & REL (Mtons) & NRL (Mtons) & $\mathrm{CO}_{2}$ (Mtons) & EGN (TWh) \\
\hline REL (Mtons & \multirow{4}{*}{2012} & 1 & 0.85974 & 0.86648 & 0.87249 \\
\hline NRL (Mtons) & & 0.85974 & 1 & 0.98524 & 0.99775 \\
\hline $\mathrm{CO}_{2}$ (Mtons) & & 0.86648 & 0.98524 & 1 & 0.97446 \\
\hline EGN (TWh) & & 0.87249 & 0.99775 & 0.97446 & 1 \\
\hline REL (Mtons) & \multirow{4}{*}{2013} & 1 & 0.87951 & 0.88855 & 0.89565 \\
\hline NRL (Mtons) & & 0.87951 & 1 & 0.98592 & 0.99895 \\
\hline $\mathrm{CO}_{2}$ (Mtons) & & 0.88855 & 0.98592 & 1 & 0.98336 \\
\hline EGN (TWh) & & 0.89565 & 0.99895 & 0.98336 & 1 \\
\hline REL (Mtons) & \multirow{4}{*}{2014} & 1 & 0.89626 & 0.91316 & 0.91220 \\
\hline NRL (Mtons) & & 0.89626 & 1 & 0.98655 & 0.99903 \\
\hline $\mathrm{CO}_{2}$ (Mtons) & & 0.91316 & 0.98655 & 1 & 0.98699 \\
\hline EGN (TWh) & & 0.91220 & 0.99903 & 0.98699 & 1 \\
\hline REL (Mtons) & \multirow{4}{*}{2015} & 1 & 0.89945 & 0.92038 & 0.91707 \\
\hline NRL (Mtons) & & 0.89945 & 1 & 0.98594 & 0.99885 \\
\hline $\mathrm{CO}_{2}$ (Mtons) & & 0.92038 & 0.98594 & 1 & 0.98795 \\
\hline EGN (TWh) & & 0.91707 & 0.99885 & 0.98795 & 1 \\
\hline REL (Mtons) & \multirow{4}{*}{2016} & 1 & 0.90685 & 0.92432 & 0.92826 \\
\hline NRL (Mtons) & & 0.90685 & 1 & 0.98612 & 0.99802 \\
\hline $\mathrm{CO}_{2}$ (Mtons) & & 0.92432 & 0.98612 & 1 & 0.99105 \\
\hline EGN (TWh) & & 0.92826 & 0.99802 & 0.99105 & 1 \\
\hline REL (Mtons) & \multirow{4}{*}{2017} & 1 & 0.92175 & 0.93392 & 0.94388 \\
\hline NRL (Mtons) & & 0.92175 & 1 & 0.98692 & 0.99664 \\
\hline $\mathrm{CO}_{2}$ (Mtons) & & 0.93392 & 0.98692 & 1 & 0.99385 \\
\hline EGN (TWh) & & 0.94388 & 0.99664 & 0.99385 & 1 \\
\hline REL (Mtons) & \multirow{4}{*}{2018} & 1 & 0.92470 & 0.94471 & 0.95030 \\
\hline NRL (Mtons) & & 0.92470 & 1 & 0.98739 & 0.99573 \\
\hline $\mathrm{CO}_{2}$ (Mtons) & & 0.94471 & 0.98739 & 1 & 0.99514 \\
\hline EGN (TWh) & & 0.95030 & 0.99573 & 0.99514 & 1 \\
\hline REL (Mtons) & \multirow{4}{*}{2019} & 1 & 0.93467 & 0.94914 & 0.95893 \\
\hline NRL (Mtons) & & 0.93467 & 1 & 0.98769 & 0.99438 \\
\hline $\mathrm{CO}_{2}$ (Mtons) & & 0.94914 & 0.98769 & 1 & 0.99611 \\
\hline EGN (TWh) & & 0.95893 & 0.99438 & 0.99611 & 1 \\
\hline REL (Mtons) & \multirow{4}{*}{2020} & 1 & 0.93012 & 0.95159 & 0.96158 \\
\hline NRL (Mtons) & & 0.93012 & 1 & 0.98791 & 0.99233 \\
\hline $\mathrm{CO}_{2}$ (Mtons) & & 0.95159 & 0.98791 & 1 & 0.99681 \\
\hline EGN (TWh) & & 0.96158 & 0.99233 & 0.99681 & 1 \\
\hline REL (Mtons) & \multirow{4}{*}{2021} & 1 & 0.93875 & 0.95468 & 0.96768 \\
\hline NRL (Mtons) & & 0.93875 & 1 & 0.9882 & 0.99076 \\
\hline $\mathrm{CO}_{2}$ (Mtons) & & 0.95468 & 0.98820 & 1 & 0.99699 \\
\hline EGN (TWh) & & 0.96768 & 0.99076 & 0.99699 & 1 \\
\hline
\end{tabular}

\section{References}

1. Hui, Z.; Danxiang, A. Environment, energy and sustainable economic growth. Proced. Eng. 2011, 21, 513-519. [CrossRef]

2. Timothy, G.W.; Michael, R.W.W.; Petar, S.V.; Jiři, J.K. Energy ratio analysis and accounting for renewable and non-renewable electricity generation: A review. Renew. Sustain. Energy Rev. 2018, 98, 328-345.

3. Bob, E.; Godfrey, B.; Stephen, P.; Janet, R. Energy Systems and Sustainability; Oxford University: New York, NY, USA, 2003.

4. Murillo, V.B.; Cassiano, M.P.; Sntonio, C.D.F. Carbon Footprint of Electricity Generation in Brazil: An Analysis of the 2016-2026 Period. Energies 2018, 11, 1412. [CrossRef] 
5. Jiang, L.; Gang, H.; Alexandria, Y. Economic rebalancing and electricity demand in China. Electr. J. 2016, 29, 48-54. [CrossRef]

6. Chen, T.L. Air Pollution Caused by Coal-fired Power Plant in Middle Taiwan. Int. J. Energy Power Eng. 2017, 6, 121-124. [CrossRef]

7. Time Series and Forecasting Methods in NCSS. Available online: https://www.ncss.com (accessed on 29 September 2018).

8. Seyed Esmaeili, F.; Rostamy-Malkhalifed, M. Data Envelopment Analysis with Fixed Inputs, Undesirable Outputs and Negative Data. J. Data Envel. Anal. Decis. Sci. 2017, 1, 1-6. [CrossRef]

9. Lawrence, M.S.; Joe, Z. Modeling Undesirable Factors in Efficiency Evaluation. Eur. J. Oper. Res. 2002, 142, 16-20. [CrossRef]

10. Ekundayo, G. Review of Sustainable Energy and Electricity Generation from Non-Rewneable Energy Sources. J. Energy Technol. Policy 2015, 5, 53-57.

11. Thomas, A.A.; Leila, H.; Pranav, B.M.; Ikenna, J.O. Comparison of $\mathrm{CO}_{2}$ Capture Approaches for Fossil-Based Power Generation: Review and Meta-Study. Processes 2017, 5, 44. [CrossRef]

12. Benjamin, D.N.; Su, L.; Jinfeng, L. Improving Flexibility and Energy Efficiency of Post-Combustion $\mathrm{CO}_{2}$ Capture Plants Using Economic Model Predictive Control. Processes 2018, 6, 135. [CrossRef]

13. Raghuvanshi, S.P.; Chandra, A.; Raghav, A.K. Carbon dioxide emissions from coal based power generation in India. Energy Convers. Manag. 2006, 47, 427-441. [CrossRef]

14. Lamiaa, A.; Tarek, E.S. Reducing Carbon Dioxide Emissions from Electricity Sector Using Smart Electric Grid Applications. J. Eng. 2013, 2013, 845051. [CrossRef]

15. Ostertagová, E.; Qstertag, O. The Simple Exponential Smoothing Model. In Proceedings of the Modelling of Mechanical and Mechatronic Systems 2011, Herlany, Slovak Republic, 20-22 September 2011.

16. Taylor, J.W. Exponential Smoothing with a Damped Multiplicative Trend. Int. J. Forecast. 2003, 19, 715-725. [CrossRef]

17. Taylor, J.W. Short-Term Electricity Demand Forecasting Using Double Seasonal Exponential Smoothing. J. Oper. Res. Soc. 2003, 54, 799-805. [CrossRef]

18. Berm'udez, J.D.; Segura, J.V.; Vercher, E. Bayesian forecasting with the Holt-Winters model. J. Oper. Res. Soc. 2010, 61, 164-171. [CrossRef]

19. Puah, Y.J.; Huang, Y.F.; Chua, K.C.; Lee, T.S. River catchment rainfall series analysis using additive Holt-Winters method. J. Earth Syst. Sci. 2016, 125, 269-283. [CrossRef]

20. Rahman, M.H.; Salma, U.; Hossain, M.M.; Khan, M.T.F. Revenue Forecasting using Holt-Winters Exponential Smoothing. Res. Rev. J. Stat. 2017, 5, 19-25.

21. Ashraf, A.S. Using Multiple Seasonal Holt-Winters Exponential Smoothing to Predict Cloud Resource Provisioning. Int. J. Adv. Comput. Sci. Appl. 2016, 7, 91-96. [CrossRef]

22. Medy, W.P.; Ema, U. Analysis of Moving Average and Holt-Winters Optimaization by Using Golden Section for Ritase Forecasting. J. Theor. Appl. Inf. Technol. 2017, 95, 6575-6584.

23. Tone, K. A slacks-based measure of efficiency in data envelopment analysis. Eur. J. Oper. Res. 2001, 130, 498-509. [CrossRef]

24. Tone, K. A slack-based measure of super-efficiency in data envelopment analysis. Eur. J. Oper. Res. 2002, 143, 34-41. [CrossRef]

25. Tone, K. Dealing with Undesirable Outputs in DEA: A Slacks-Based Measure (SBM) Approach; National Graduate Institute for Policy Studies: Tokyo, Japan, 2003.

26. Kuo, H.F.; Chen, H.L.; Tsou, K.W. Analysis of Farming Environmental Efficiency Using a DEA Model with Undesirable Outputs. APCBEE Procedia 2014, 10, 154-158. [CrossRef]

27. Goto, M.; Takahashi, T. Operational and Environmental Efficiencies of Japanese Electric Power Companies from 2003 to 2015: Influence of Market Reform and Fukushima Nuclear Power Accident. Math. Probl. Eng. 2017, 2017, 4936595. [CrossRef]

28. Ozkan, N.F.; Ulutas, B.H. Efficiency analysis of cement manufacturing facilities in Turkey considering undesirable outputs. J. Clean. Prod. 2017, 156, 932-938. [CrossRef]

29. BP Statistical Review of World Energy. Available online: https://www.bp.com (accessed on 30 September 2018).

30. Nonrenewable Sources. Available online: https:// www.eia.gov (accessed on 28 September 2018).

31. Renewable Sources. Available online: https:/ / www.eia.gov (accessed on 28 September 2018). 
32. Beverton, R.J.H.; Sidney, J.H. On the Dynamics of Exploited Fish Populations; Great Britain Fishery Investment: London, UK, 1957.

33. Winter, P.R. Forecasting Sale by Exponentially Weighted Moving Averages. Manag. Sci. 1960, 6, $324-342$. [CrossRef]

34. Lewis, C.D. Industrial and Business Forecasting Methods: A Practical Guide to Exponential Smoothing and Curve Fitting; Butterworth Scientific: London, UK, 1982.

35. López, F.J.; Ho, J.C.; Ruiz-Torres, A.J. A computational analysis of the impact of correlation and data translation on DEA efficiency score. J. Ind. Prod. Eng. 2016, 33, 192-204. [CrossRef]

36. Robert, J.P. Cutting carbon emissions from electricity generation. Electr. J. 2017, 30, 41-61. [CrossRef]

37. Badunenko, O.; Tauchmann, H. Simar and Wilson Two-Stage Efficiency Analysis for Stata; FriedrichAlexander-Universität Erlangen-Nürnberg, Institute for Economics: Erlangen, German, 2018.

(C) 2018 by the authors. Licensee MDPI, Basel, Switzerland. This article is an open access article distributed under the terms and conditions of the Creative Commons Attribution (CC BY) license (http://creativecommons.org/licenses/by/4.0/). 